\title{
Cavobipulmonary shunt for the management of isolated postinfarction right ventricular failure
}

\author{
Afksendiyos Kalangos, MD, PhD, FETCS, Stéphane Reverdin, MD, Constantinos Roussos, MD, Dominique Vala, MD, \\ and Mustafa Cikirikcioglu, MD, PhD, Geneva, Switzerland
}

$\mathrm{R}$ ight ventricular (RV) infarction, which is now recognized to occur in approximately $50 \%$ of all inferior myocardial infarctions (MIs), ${ }^{1}$ has a significant early mortality in patients with RV dysfunction. ${ }^{2,3}$ In this article we report the midterm results of 3 patients who had isolated $\mathrm{RV}$ failure after acute inferior MI and in whom a cavobipulmonary shunt was carried out to reestablish an adequate left ventricular (LV) filling and decrease the RV volume overload in the presence of significant tricuspid regurgitation.

\section{Clinical Summaries}

PATIENT 1. In 1999, a 56-year-old man who had acute inferior MI complicated with RV shock was first treated with thrombolytic therapy and the following day underwent successful balloon angioplasty with stent placement in the proximal segment of the right coronary artery (RCA). RV failure persisted despite the use of vasopressors and an LV ejection fraction (LVEF) estimated at $50 \%$. Transthoracic echocardiography (TTE) showed a dilated and poorly contracting right ventricle and moderate tricuspid regurgitation. Right heart catheterization confirmed physiologic pulmonary pressure values $(25 / 12 \mathrm{~mm} \mathrm{Hg}$; mean, $15 \mathrm{~mm} \mathrm{Hg})$. A cavobipulmonary connection was then performed on a beating heart during cardiopulmonary bypass (CPB) 1 week after the onset of the MI, allowing for rapid discontinuation of vasopressors and hemodynamic improvement, despite prolonged drainage of pleural effusions. Five years later, the patient is in New York Heart Association (NYHA) class I with a trivial tricuspid regurgitation, despite persistent global RV hypokinesia.

PATIENT 2In 2000, a 65-year-old woman had acute MI and underwent balloon angioplasty with stent placement in the proximal segment of the RCA, as well as in the left anterior descending artery (LAD) distal to the first septal branch. Two months later, she was admitted to the hospital with signs of congestive RV failure. TTE showed a dilated and poorly contracting RV, moderate-tosevere tricuspid regurgitation, and akinesia of the inferior $\mathrm{LV}$ wall. Repeat coronary angiography confirmed the patency of the stented

\footnotetext{
From the Clinic for Cardiovascular Surgery, University Hospital of Geneva, Switzerland.

Received for publication Jan 17, 2005; accepted for publication Feb 8, 2005.

Address for reprints: Afksendiyos Kalangos, MD, PhD, FETCS, Clinic for Cardiovascular Surgery, University Hospital of Geneva, 24, rue Micheli-du-Crest, 1211 Geneva 17, Switzerland (E-mail: afksendyios.kalangos@ hcuge.ch).

J Thorac Cardiovasc Surg 2005;130:572-3

$0022-5223 / \$ 30.00$

Copyright $\odot 2005$ by The American Association for Thoracic Surgery

doi:10.1016/j.jtcvs.2005.02.004
}

RCA and LAD. LVEF was estimated at $45 \%$. Right atrial pressure was $23 \mathrm{~mm} \mathrm{Hg}$, and mean pulmonary pressure was $14 \mathrm{~mm} \mathrm{Hg}$. A cavobipulmonary connection with concomitant tricuspid annuloplasty using a No. 28 Carpentier-Edwards ring (Edwards Lifesciences, Irvine, Calif) was then performed on the beating heart during $\mathrm{CPB}$, resulting in spectacular clinical improvement within 1 month after the operation. The last echocardiographic control (4 years after the operation) showed mild tricuspid regurgitation and normalized RV dimensions despite persistent RV hypokinesia. LVEF was estimated at 55\% at discharge and has remained at this value throughout the follow-up period. The patient is actually in NYHA class I.

PATIENT 3In 2003, a 48-year-old woman had an acute MI and underwent balloon angioplasty, with 2 stents placed in the proximal segment of the RCA the following day. During the 4 months after her infarction, she became progressively dyspneic, despite treatment with an angiotensin-converting enzyme inhibitor. TTE showed a dilated right ventricle with extended akinesia of its free wall, severe tricuspid regurgitation with no pulmonary hypertension, paroxysmal interventricular septal motion, and inferobasal dyskinesia of the left ventricle. Three months later, she was admitted to our institution because of progressive signs of congestive RV failure despite maximal medical treatment. Subsequent coronary angiography showed occlusion of the stented proximal segment of the RCA with retrograde opacification by the LAD. LVEF was estimated at $40 \%$. Right atrial pressure was $18 \mathrm{~mm} \mathrm{Hg}$, and mean pulmonary pressure was $15 \mathrm{~mm} \mathrm{Hg}$. A cavobipulmonary connection with concomitant tricuspid annuloplasty using a No. 28 Carpentier-Edwards ring and coronary bypass grafting to the RCA was performed during CPB on a beating heart. One year later, she is in NYHA class I. At the last echocardiographic follow-up examination, despite the persistence of RV and inferior LV wall akinesia, the degree of tricuspid regurgitation was mild to moderate. The LVEF has significantly improved (50\%) after surgical intervention and remained stable during the follow-up period.

\section{Discussion}

Since RV infarction has been recognized as a clinical syndrome, hemodynamic data, the high incidence of occlusion of the proximal segment of the RCA as the infarct artery, and a relatively preserved LV function have served to confirm diagnosis. Berger and colleagues ${ }^{2}$ reported that mortality during the first year after discharge among the patients who had RV dysfunction was twice that of the patients without RV dysfunction. Preserved LV function observed in the early phase of isolated postinfarction RV failure might later be impaired by the diastolic leftward displacement of the interventricular septum generated by the isolated RV volume overload caused by tricuspid regurgitation. ${ }^{4}$ Moreover, in the setting of tricuspid regurgitation, the left atrium can be compressed 
by the leftward bulging of the interatrial septum during RV systole, hence reducing left atrial stroke volume and further LV filling. ${ }^{5}$

The cavobipulmonary shunt diverts between $30 \%$ and $40 \%$ of the systemic venous return from the right ventricle. Its beneficial effects are related to increasing LV filling in the presence of RV dysfunction and decreasing the RV wall stress and work index proportional to the decrease in preload. In the first patient, who was operated on during the acute phase of isolated postinfarction RV failure, the rapid postoperative hemodynamic improvement was due to the increased systemic output, rather than to the improvement of systolic performance of the left ventricle, which played a more important role in the other 2 patients who came to surgical intervention later with significant tricuspid regurgitation. The improvement of their postoperative LVEF was certainly due to the additional beneficial effects of RV decompression, hence normalizing interventricular septal motion, increasing left atrial volume, and subsequently achieving effective volume loading of the left ventricle.

We believe that performing a cavobipulmonary shunt in the setting of either the acute or chronic phase of postinfarction congestive RV failure offers a promising and useful therapeutic option.

\section{References}

1. Kinch JW, Ryan TJ. Right ventricular infarction. $N$ Engl J Med. 1994;330:1211-7.

2. Berger PB, Ruocco NA Jr, Ryan TJ, Jacobs AK, Zaret BL, Wackers FJ, et al. Frequency and significance of right ventricular dysfunction during inferior wall left ventricular myocardial infarction treated with thrombolytic therapy (results from the Thrombolysis In Myocardial Infarction (TIMI) II trial). Am J Cardiol. 1993;71:1148-52.

3. Pfisterer M, Emmenegger H, Soler M, Burkhart F. Prognostic significance of right ventricular ejection fraction for persistent complex ventricular arrhythmias and/or sudden cardiac death after first myocardial infarction: relation to infarct location, size, and left ventricular function. Eur Heart J. 1986;7:289-98.

4. Hurwitz A. Left ventricular function in infants and children with symptomatic Ebstein's anomaly. Am J Cardiol. 1994;73:716-8.

5. Louie EK, Bieniarz T, Moore AM, Levitsky S. Reduced atrial contribution to left ventricular filling in patients with severe tricuspid regurgitation after tricuspid valvulectomy: a Doppler echocardiographic study. J Am Coll Cardiol. 1990;16:1617-24.

\title{
Surgical approach to aortic root lesions in patients with homozygous familial hypercholesterolemia and Takayasu arteritis
}

\author{
Stéphane Aubert, MD, Nicolas Bonnet, MD, Pascal Leprince, MD, Théodoro Barreda, MD, Alain Pavie, MD, and \\ Iradj Gandjbakhch, MD, Paris, France
}

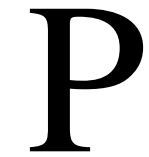
atients with homozygous familial hypercholesterolemia (HFH) and Takayasu arteritis are commonly affected by a severe aortic root calcification associated with coronary ostial stenosis. In these patients a long-term outcome of the coronary artery bypass graft is a permanent preoccupation because of the high risk of progressive arteriosclerosis after surgical repair. We propose an enlargement plasty of the proximal segment of the coronary arteries with a saphenous patch, followed

From the Department of Cardiovascular Surgery, Pitié Salpêtrière Hospital, Paris, France.

Presented at the French Society of Thoracic and Cardio-vascular Surgery's Journées d'automne, December 3, 2004.

Received for publication Dec 31, 2004; revisions received Jan 21, 2005; accepted for publication Feb 8, 2005.

Address for reprints: Stéphane Aubert, MD, Department of Cardiovascular Surgery, Pitié Salpêtrière Hospital, 47-83 boulevard de l'hôpital, 75651 Paris Cedex 13, France (E-mail: stephaneaubert@yahoo.fr).

J Thorac Cardiovasc Surg 2005;130:573-4

$0022-5223 / \$ 30.00$

Copyright $\odot 2005$ by The American Association for Thoracic Surgery

doi:10.1016/j.jtcvs.2005.02.006 by an aortic root replacement with a composite tube graft and coronary reimplantation.

\section{Clinical Summary}

Two patients with HFH and 1 with Takayasu arteritis had severe aortic root calcifications associated with coronary ostial stenosis (1 male and 2 female patients; mean age, $30 \pm 14$ years). Mean aortic gradient ranged from 30 to $70 \mathrm{~mm} \mathrm{Hg}$, with a valvular stenosis in 1 and a supravalvular aortic stenosis in all. All 3 patients had severe ostial coronary stenosis observed by systematic catheterization (occlusion in the case of one right coronary artery). Only 1 patient had angina on effort, with the others being asymptomatic.

At the time of the operation, cardiopulmonary bypass was performed between the right atrium and the aortic arch. Retrograde cold blood was used to achieve cardioplegic arrest. On opening the ascending aorta, severe calcifications of the aortic wall were observed, compromising the lumen. Examination of the aortic root revealed a calcified trileaflet valve in all patients, with significant aortic stenosis in 1 patient. The aorta was divided transversally above the ostia of the coronary arteries. The aortic valve was excised, and the remaining aortic annulus was cleaned of calcium deposits. The coronary arteries were detached, and each was opened longitudinally $1 \mathrm{~cm}$, including an occluded right coronary artery in 1 patient. The coronary artery lumina were enlarged with an oval-shaped patch of saphenous vein (Figure 1). A St Jude 